\title{
On the Effects of Social Class on Language Use: A Fresh Look at Bernstein's Theory
}

\author{
Mohammad Aliakbari (Corresponding author) \\ Dept. of English, Ilam University PO Box 516, Ilam 69315, Iran \\ E-mail: maliakbari@hotmail.com \\ Nazal Allahmoradi \\ Dept. of English, Ilam University PO Box 516, Ilam 69315, Iran \\ E-mail: n_allahmoradi@yahoo.com
}

Doi:10.7575/aiac.alls.v.5n.3p.82

Received: $31 / 03 / 2014$

URL: http://dx.doi.org/10.7575/aiac.alls.v.5n.3p.82

Accepted: 13/05/2014

\begin{abstract}
Basil Bernstein (1971) introduced the notion of the Restricted and the Elaborated code, claiming that working-class speakers have access only to the former but middle-class members to both. In an attempt to test this theory in the Iranian context and to investigate the effect of social class on the quality of students language use, we examined the use of six grammatical categories including noun, pronoun, adjective, adverb, preposition and conjunction by 20 workingclass and 20 middle-class elementary students. The results of Chi-square operations at $\mathrm{p}<.05$ corroborated Bernstein's theory and showed that working- class students were different from middle-class ones in their language use. Being consistent with Bernstein's theory, the results obtained for the use of personal pronouns indicated that middle-class students were more person-oriented and working-class ones more position-oriented. Findings, thus, call for teachers' deliberate attention to learners' sociocultural variation to enhance mutual understanding and pragmatic success.
\end{abstract}

Keywords: Elaborated code, Restricted code, Person-oriented, Position-oriented, Social class

\section{Introduction}

The relationship between language and social class is both theoretically and empirically a key issue in critical discourse studies and sociolinguistic research. A major concern in the analysis of language and social class has been how language variation acts as a marker and instrument for social and racial stratification. As a result, language has been analyzed variously by linguists and sociologists. In the1970s, the British sociologist, Basil Bernstein conducted a study of working- and middle-class children. He argued for the existence of two quite distinct varieties of language use in society: the elaborated code and the restricted code, which he claimed to account for the relatively poor performance of working-class pupils in language-based subjects while they were scoring just well as their middle-class peers in mathematical subjects.

According to Atherton (2002), the essence of the distinction between the two codes is in what language is suited for. The restricted code works better than the elaborated code in situations where there is a great deal of shared and takenfor-granted knowledge in the group of speakers. This code is economical and rich, conveying a vast amount of meaning with few words, each of which has a complex set of connotations and acts like an index, pointing the hearer to a lot more information which remains unsaid. On the contrary, the elaborated code spells everything out, not because it is better, but because it is necessary so that everyone (can) understand it. It has to elaborate because the circumstances do not allow the speaker to condense. The elaborated code works well in situations where there is no prior or shared understanding and knowledge, where more thorough explanation is required. If one is saying something new to someone $\mathrm{s} /$ he has never met before, s/he would most certainly communicate it in the elaborated code. Spring (2002). The sections that follow aim at shedding more light on Bernstein's theory through analyzing the effects of social class on language use in general and on his proposed dichotomies between the two linguistic codes and modes of socialization (personal and positional) in particular.

\section{Theoretical Framework}

Bernstein's (1971) theory can be explained in terms of three basic concepts of language codes, class, and control. He reformulated Restricted and Elaborated codes. The restricted code "employs short, grammatically simple, and often unfinished sentences of poor syntactic form; uses few conjunctions simply and repetitively; employs little subordination; tends toward a dislocated presentation of information; is rigid and limited in the use of adjectives and adverbs, makes infrequent use of impersonal subject pronouns; confounds reasons and conclusions; uses idioms frequently and makes frequent appeals to "sympathetic circularity" (Wardhaugh, 1992: 317).

In contrast, the elaborated code "makes use of accurate grammatical order and syntax to regulate what is said; uses complex sentences that employ a range of devices for conjunction and subordination; employs prepositions to show relationships of both a temporal and logical nature; shows frequent use of the pronoun I; uses with care a wide range of adjectives and adverbs; is likely to arise in a social relationship which raises the tension in its members to select from their linguistic resources a verbal arrangement which closely fits specific referents" (Wardhaugh, 1992: 317). 
'Control' refers to the role of families and their social control, the way of decision making in families and the relationship among the members. Bernstein (1972b) made a distinction between position-oriented and person-oriented families. In the former, language use is closely related to such matters as close physical contact among the members, a set of shared assumptions, and a preference for implicit rather than explicit meaning in communication. In personoriented families, on the other hand, language use depends on these factors less, and communication is more explicit and context-free. That is, it is less dependent for interpretation on such matters as physical surroundings. According to Bernstein, position orientation leads to a strong sense of social identity with some loss of personal autonomy, whereas person orientation fosters personal autonomy. Wardhaugh (1992, P. 360)

Finally, Bernstein used Brandis's (1970) Social Class Index through which he analyzed the working-class and the middle-class by considering the frequencies of use of grammatical categories. The present study also uses these concepts and frameworks in its investigation of the relationship between language use and one's social class.

\section{Review of the Literature}

Bernstein's theory of language codes is perhaps one of the most challenging theories in sociolinguistics in that it received both support and criticism in the field. Influenced by his ideas, many researchers have commented on the different ways in which adults from various social classes respond linguistically to their children. Hess and Shipman (1965) studied middle-class and lower working-class mothers, helping their four-year-old children in either blocksorting tasks or the use of Etch-A-Sketch. The study revealed important differences, with the middle-class mothers far better able to help or instruct their children than the lower working-class ones, who were unable to offer much assistance to their children. Robinson and Rackstraw (1967) also found that middle-class mothers, far more often than the lower working-class mothers, tried to answer their children's Wh-questions (which are considered as information seeking questions) with genuine explanations. Bernstein and Henderson (1969) reported social class differences in the emphasis placed on the use of language in two areas of children's socialization: interpersonal relationships and the acquisition of basic skills. The results showed that middle-class mothers placed much greater emphasis on the use of language in the person area, relative to their working class counterparts, whereas working-class mothers put greater emphasis on the use of language in the transmission of basic skills. Newson and Newson (1970) found that working class mothers invoke authority figures such as police officers in threatening their children. Cook (1971) found that lower working-class mothers used more commands to their young children and often relied on their positional authority to get their way than did middle-class mothers, who preferred to direct their children attention to the consequences of what they were doing.

To search for a relationship between social class and mothers' speech, Henderson (1972) investigated the language used by a hundred mothers to their seven-year-old children. The mothers were divided into middle-class and working-class groups. He reported that relative to the working-class mothers, the middle-class mothers favored the use of abstract definitions, explicit rather than implicit definitions, and information giving strategies in answering children's questions. They also used language to transmit moral principles and to indicate feelings. In Jay, Routh and Brantley's (1980) study twenty-five mothers of all social class levels were asked to tell, as if to a six-year-old child, stories suggested by several cartoon picture sequences. These stories were then played to a hundred six-year-old children of high and low social class levels, who were then asked standard comprehension questions about their content. An analysis of the comprehension scores revealed a significant main effect of the social class of the adult speakers and of the social class of the child listeners.

In a more recent study, Rodríguez and Hines Montiel (2009) tried to describe and compare the communication behaviors and interactive reading strategies used by Mexican American mothers of low and middle socioeconomic status (SES) backgrounds during shared book reading with their preschool children. Significant differences between different SES groups regarding the frequency of specific communication behaviors were revealed. Middle-SES mothers used positive feedback and yes/no questions more often than did low-SES mothers. Mexican American mothers also used a variety of interactive reading strategies with varying frequencies, as measured by the Adult/Child Interactive Reading Inventory. They enhanced attention to text some of the time, but rarely promoted interactive reading/supported comprehension or used literacy strategies.

All the above-mentioned studies were concerned with how adults from different social classes respond linguistically to their children. The results of these studies are consistent with that of Bernstein's. Moreover, reference can be made to many studies and programs which addressed the language for children and socialization. Likewise, in the available literature, references have been made to the studies that differentiated between restricted and elaborated language codes and addressed the consequences they hold for those who use them.

Williams (1969) tried to determine whether statistically reliable social class differences could be found in the degrees and types of syntactic elaboration in the speech of selected Negro and White, male and female, fifth-and-sixth-grade children from whom language samples had been obtained in the Detroit Dialect study. The corpus of some 24,000 words represented the speech of children selected from relatively low and middle ranges of a socioeconomic scale used in the original study. A quantitative description of syntactic elaboration was obtained by using a modified immediate constituents procedure which provided coding of the structural divisions of English sentences. The results indicated that children from the higher-status sample tended to employ more, and more elaborated, syntactic patterns. Such status differences generally prevailed across the sexes, but did vary across the levels of a topical variable and the race variable. Lareau (2002) examined the effects of social class on the interaction inside the home upon ten-year-old black and white children. The results showed that middle-class parents emphasized concerted cultivation through efforts to foster children's talents via organized leisure activities and extensive reasoning. Working-class and poor parents appeared to accept the accomplishment of natural growth, providing conditions under which children can grow but leaving leisure activities to children themselves. These parents also used directives rather than reasoning. Middle-class children, both white and black, were gaining an emerging sense of entitlement from their family life. Working-class and poor children did not display the same sense of entitlement or advantages. 
Aarefi (2008) investigated the difference between linguistic-cognitive skills in Turkish and Kurdish students with Farsi as their mother tongue from different economical-social backgrounds, using Vygotsky's theory of general cognitive development and Bernstein's theory of social class and differences in speech quality. She found that the average number of words the middle socioeconomic children level used was far higher than the average number of words the children from low socioeconomic class used. The language skill in using words by the Turkish and Kurdish speaking children had no relationship with their cultural backgrounds. There was also a significant difference between the parents' level of education; children whose parents had a higher level of education used more words in writing. Aliakbari et al. (2012) conducted a research project on fifth graders in Tehran, Iran and analyzed both the language and the social class data. The results of the correlation analyses indicated a significant relationship between the total social class scores and certain grammatical categories. The relationships between the language data and the social class factors also displayed a similar trend. They, thus, concluded that their findings supported Bernstein's theory to a great extent.

In spite of the fact that many studies confirmed Bernstein's ideas, there are also some critics in the literature. Rosen (1972) criticized Bernstein on the grounds that he had not looked closely enough at working-class life and language. Labove (1972) argued that one cannot reason from the kind of data presented by Bernstein that there is a qualitative difference between the two kinds of speech Bernstein describes, let alone a qualitative difference that would result in cognitive and intellectual differences.

Cooper (1976) examined aspects of Basil Bernstein's sociolinguistic account of educational failure empirically. Two groups of students from the first year of an upper school in England, one with primarily non-manual backgrounds, the other with primarily manual backgrounds, were observed in math and science classrooms, through informal discussions with teachers, and through school records and reports, to determine which of Bernstein's two codes appeared to underlie the disciplinary and pedagogic technique of the teachers of the classes observed. The findings showed that in terms of indicators for both regulative and instructional content, the observed math and science curricula appeared to be predicated on a restricted rather than an elaborated code for both classes of students. He concluded that Bernstein's emphasis on certain pupils lacking an elaborated code accounting for working-class failure and middle-class success is misplaced. Thorlindsson (1987) also made an attempt to test Bernstein's sociolinguistic model empirically. The relationship was examined among all the major variables of the model including social class, family interaction, linguistic elaboration, IQ, and school performance. The correlations among social class, family interaction, IQ, and school performance were along the lines hypothesized by Bernstein, whereas linguistic elaborations did not play their predicted role. The empirical results indicated that an important revision of the model was needed. Findings, thus, suggested that a clear distinction should be made between cognitive and pragmatic aspects of the sociolinguistic codes, and between macro and micro elements of social structure.

Bolander (2009), assessing the relevance of Bernstein's theory for German-speaking Switzerland, showed that the uptake of Bernstein's outlook was and continues to be minimal for the Swiss German context and explores reasons for this conclusion. Acknowledging that certain aspects of Bernstein's theoretical outlook are potentially relevant for the Swiss German context in light of the contemporary studies which highlight a connection between social background and differential school achievement, he concludes that they need to be reassessed in light of the awareness of the variety of interdependent factors which can and do influence the performance of children and adolescents at school.

As posited earlier and is clearly understood from the literature reviewed, Bernstein's theory has attracted the attention of many researchers and sociolinguists. Yet, in spite of all these studies, one cannot determine with certainty how social class affects language use.

\section{Focus of the Study}

Bernstein claims that working class students have access only to restricted codes and middle class students to both restricted and elaborated codes, because middle-class members are geographically, socially, and culturally mobile. His theory has inspired a good number of studies. In order to take a different measure in this relation, the present study intends to investigate the use of grammatical categories of noun, pronoun, adjective, adverb, preposition and conjunction among working-class and middle-class children. The result of this study is hoped to raise teachers' understanding of the effect of social class on students' language use and determine whether they should consider it in their educational programs or not.

\section{Research Questions}

This study seeks answer to the following questions:

1- Does social class affect ones use of grammatical categories in L1 writing?

2- How different are middle- and working-class students in their social control with reference to their use of personal pronouns?

\section{Methodology}

\subsection{Participants}

100 female students aged between 9 and 11 took part in the study. They were third or fourth grade elementary students in the city of Eivan in the province of Ilam, in western Iran. The reason for selecting students at these levels was that practicing writing tasks, which is the channel of instrumentation in this study, is part of their educational programs of these levels. Of these 100 participants, based on a social class questionnaire, 20 middle class and 20 working class students were selected.

\subsection{Instruments}

In conducting the present study two instruments have been adopted to collect the data. To determine students' social class, a converted version of Wilftang's (1990) questionnaire was administered. Different views on factors to be included in determining one's social class were considered and to make it suitable for the context of the study several open-ended questions were added. After translation and revision, it was piloted, re-examined and finally administered as an 11-item social class questionnaire (a copy of which is provided in Appendix A), comprising 10 multiple-choice questions with a variable number of choices and one open-ended question (each choice is indicative of a different level 
of social class). The questionnaire was completed by the students themselves. Because some students avoided expressing their fathers' job, in order to be sure of the correctness of their answers, it was completed by their parents as well. Another measure used in this study was Picture sequences which required the students to write a story in an equal time space to examine their language use differences. It was the same picture sequences used by Bernstein in his original study (a copy is provided in appendix B). Such an analysis was used in Bernstein's studies but instead of written description he used a verbal description of the picture cards.

\subsection{Data Collection}

The social class questionnaire was administered to the students who were already familiar with writing tasks. They, then, received selected pictures and wrote their stories in an equal time space. All grammatical categories of noun, pronoun, adjective, adverb, preposition and conjunction were counted manually by the researchers. To ensure the reliability of the scoring, correlation coefficient was measured for each category. The result which ranged from .79 to .88 was evaluated as moderate reliability, in line with Farhady, Ja'farpur, and Birjandi (2006). To check whether the differences between the frequencies of grammatical categories for working-class and middle-class groups were significant, separate chi-square tests were run. Moreover, to determine subjects' social control, uses of personal pronouns by both groups were compared and their frequencies computed as well.

\section{Results}

Using SPSS software, descriptive statistics including frequency, mean and standard deviation of each category were computed for two groups of participants. As can be seen in Table 1 below, the means and the standard deviation of both groups differed.

\begin{tabular}{llll}
\multicolumn{3}{l}{ Table 1. Descriptive statistics for use of grammatical categories among two social classes } \\
\hline Grammatical Category & Social class & Mean & Std. Deviation \\
\hline Noun & Middle & 33.05 & 11.413 \\
& & & \\
\multirow{4}{*}{ Adjective } & Working & 29.05 & 10.190 \\
& Middle & 3.30 & 2.080 \\
Adverb & Working & 2.05 & 1.905 \\
& Middle & 8.75 & 3.796 \\
Preposition & Working & 6.50 & 4.560 \\
& Middle & 9.85 & 4.234 \\
pronoun & Working & 7.65 & 4.258 \\
& Middle & 4.15 & 3.031 \\
\multirow{2}{*}{ Conjunction } & Working & 4.45 & 4.442 \\
& Middle & 9.30 & 6.233 \\
& Working & 7.85 & 6.800 \\
\hline
\end{tabular}

In order to answer the question of the study, first, all linguistic categories in students' writings of both groups were counted. Then, 6 chi-square tests were run to compare the differences between the frequencies of the grammatical categories. As is noticeable from the results in Table 2, for all six grammatical categories, the observed $\chi^{2}$ is greater than critical $\chi^{2}$. Accordingly, it can be claimed that the participants' social class has influenced their language use.

Table 2. Chi-square results for comparing the frequencies of grammatical categories of the groups

\begin{tabular}{llll}
\hline $\begin{array}{l}\text { Grammatical } \\
\text { Categories }\end{array}$ & chi square & Sig & P Level \\
\hline Nouns & & & \\
Adjectives & 5.153 & .23 & $<.02$ \\
Adverbs & 3.574 & .59 & $<.03$ \\
Pronouns & 8.758 & .03 & $<.03$ \\
Propositions & 4.313 & .38 & $<.01$ \\
Conjunctions & 6.481 & .11 & $<.05$ \\
\end{tabular}

To determine students' social control and answer the second question, the use of personal pronouns between the two social classes was analyzed. As Table 3 indicates, the frequency of the use of personal pronouns by the middle-class subjects is higher than that of the working-class participants. The use of the third-person plural pronoun 'they' and the first person singular ' $\mathrm{I}$ ' had the highest frequencies among middle-class students. The second person plural 'you' and the third person singular 'he/she' had the lowest frequencies. For the working-class members, the most frequently used pronouns were 'they' and the first person plural 'we'. In order to find out whether differences between the uses of the personal pronouns were significant, six chi-square tests were run. The difference was significant only for the use of the first person singular 'I'. These results somehow corroborate Bernstein's theory, which maintains that users of the elaborated code make frequent use of the pronoun 'I' and are person-oriented while users of the restricted code are position oriented. The working-class participants gave more importance to the third person plural and the first person plural, which signifies that they paid more attention to group work and shared assumptions and were more positionoriented. The frequency of using the first person singular pronoun 'I' among the middle-class subjects indicated that they are more person-oriented. 


\begin{tabular}{lllll}
\multicolumn{5}{l}{ Table 3. Frequency of the use of personal pronouns among the groups } \\
\hline & Middle class & Working class & Chi-square & Level of Significance \\
\hline I & 19 & 3 & 11.636 & .001 \\
You(singular) & 10 & 7 & .529 & .46 \\
He/She & 9 & 8 & .059 & .808 \\
We & 14 & 9 & 1.087 & .297 \\
You(plural) & 10 & 7 & .529 & .46 \\
\hline They & 34 & 42 & .842 & .359 \\
\hline
\end{tabular}

\section{Discussion and Conclusion}

This study took a fresh look at Bernstein's theory and the question whether social class differences can produce different language use. To this aim, frequency of the use of grammatical categories of noun, pronoun, adjective, adverb, proposition and conjunction by 20 working class and 20 middle class elementary students were compared. Chi-square results corroborated Bernstein's theory regarding the effect of social class on language use. The findings of the study can be explained by referring to Bernstein's Elaborated and Restricted codes. Working-class students have access to the restricted codes, the ones they reveal in the socialization process where the values reinforce such codes but middle class have access to both restricted and elaborated codes. Another question of this study was related to the social control of the middle- and working-class students based on their use of personal pronouns. The most outstanding result in the use of personal pronouns was the use of the first person singular pronoun 'I' by middle class students. The results again certified Bernstein's theory on the grounds that the working-class members are more position-oriented and give more attention to group work and shared assumption and that middle-class students are far more person-oriented and tend towards personal autonomy.

The results accordingly corroborated Bernstein's theory in that restricted and elaborated codes are indicative of different social classes. It also shows how complex the educational matters are that teachers should consider. It implies that teachers and program developers should consider learners' social class differences, design correct curriculum to help working class students achieve elaborated codes, and look for ways to hinder the waste of student's talent in the lower social class.

\section{References}

Aarefi, Marzieh: Investigation on linguistic-cognitive skills of bilingual children with different economical-cultural backgrounds, Quarterly Journal of Educational Innovations, 2008.

Aliakbari, Mohammad. Samaie, Mahmoud. Sayehmiri, Kourosh and Qaracholloo, Mahmoud.: The Grammatical Correlates of Social Class Factors: The Case of Iranian Fifth-Graders, Linguistikonline, 2012.

Atherton, J.: Language Codes. Available Online at: http://www.doceo.co.uk/language codes.htm, 2002.

Bernstein, Basil: Social Structure, Language and Learning, Educational Research, 1961.

Bernstein, Basil: Class, Codes and Control, London: Routledge \& Kegan Paul, 1971.

Bernstein, Basil: A Sociolinguistic Approach to Socialization: with some Reference to Educability, In J. Gumperz and D. Hymes (Eds.), Directions in Sociolinguistics: The Ethnography of Communication (pp. 465-497), New York: Holt, Rinehart and Winston, 1972a.

Bernstein, Basil, \& Henderson, D: Social Class Differences in the Relevance of Language to Socialization, Sociology, 1969.

Bolander, Brook: On the Relevance of Bernstein for German-speaking, Switzerland. Journal of Cross-Cultural and Interlanguage Communication, 2009.

Cook, John: An Inquiry into Patterns of Communication and Control between Mothers and their Children in Different Social Classes, London University, 1971.

Cooper, Barry: Bernstein's Codes: A Classroom Study, University of Essex Occasional Paper Education Area, ERIC, 1976.

Farhady, Hossein, Ja'farpur, Abdoljavad, \& Birjandi, Parviz: Testing Language Skills: From Theory to Practice, Tehran, 2006.

Henderson, Dorothy: Contextual Specificity, Discretion and Cognitive Socialization: With Special Reference to Language, Sociology, 1972.

Hess, Robert. D, Shipman, Virginia. C: Early Experience and the Socialization of Cognitive Modes in Children, Child Development, 1965.

Jay, Susan. M, Routh, Donald. K, Brantley, John. C: Social Class Differences in Children's Comprehension of Adult Language, Journal of Psycholinguistic Research, 1980.

Labov, William: Language in the Inner City: Studies in the Black English Vernacular, Philadelphia: University of Pennsylvania Press, 1972.

Lareau, Annette: Invisible Inequality: Social Class Childrearing in Black families and White Families, American Sociological Review, 2002.

Newson, John. \& Newson, Elizabeth: Four Years Old in an Urban Community, Harmondsworth: Penguin, 1970.

Rodríguez, Barbara L. \& Hines, Rachel. And Montiel, Miguel: Mexican American Mothers of Low and Middle Socioeconomic Status: Communication Behaviors and Interactive Strategies during Shared Book Reading, LSHSS Journal, 2009.

Robinson, W. P. \& Rackstraw, S. J: Variations in Mothers' Answers to Children's Questions, Sociology, 1967.

Rosen, Harold: Language and class: a critical look at the theories of Basil Bernstein, Bristol: Falling Wall Press, 1972. 
Spring, R. Young: Basil Bernstein's Sociolinguistic Theory of Language Codes, Retrieved 17 December from: Zimmercsu (vesno.edv/bohnca/spch/oo/3-3bersnstein.htm, 2002.

Thorlindsson, Thorolfur: Bernstein's Sociolinguistics: An Empirical Test in Iceland, Social Forces, 1987.

Wardhaugh, Ronald: An Introduction to Sociolinguistics, Cambridge, MA: Blackwell, 1992.

Wiltfang, Gregory L: Social Class and Adolescents' Self-esteem: Another Look, Social Psychology Quarterly, 1990.

Williams, Frederick: Social Class Differences in Children's Syntactic Performance: A Quantitative Analysis of Field Study Data, Journal of Speech and Hearing Research, 1969.

\section{Appendix A \\ Translation of Social Class Questionnaire}

Dear Respondent:

The present questionnaire has been prepared for a research project. All information you provide will be kept confidential. Please read every question carefully and choose the one that fits you best. Then tick the suitable choice. Thank you for your cooperation.

1. How many persons are there in your family?

Three persons

Four persons

Five persons

More than five persons

2. Is there any one in your family who participates in art, sports, or foreign language education classes?

Yes

No

3. Which of the following items describe the properties of your family? (Tick the ones you have(

Royal curtain

MDF cabinet

House

$\operatorname{Car}(\mathrm{s})$

Land property

Furniture

LCD TV

4. What is the type of housing you are currently living in?

Renting

Private housing (from brick)

Private housing (concrete)

Private housing (from marble)

Government provided

5. What is your parents' job?

6. What is your father's level of education?

Illiterate

Below diploma

Diploma

$\mathrm{BA} / \mathrm{BS}$

MA/MS

PHD

7. How would you describe your neighborhood's condition of living?

Luxurious

Comfortable

Average

Below average

Run down

8. How much time during the past 3 years has your father been out of work?

More than 1 year

Less than 1 year

Not at all

9. Have your parents received welfare payments? If yes which type of welfare?

Yes, Relief committee

Yes, Disabled tuition

Yes, Social security

No

10 How often do you buy clothes?

Twice a year

Five times a year

Eight times a year

More than eight times

11. How much is your parents' salary?(In Toman) 
100-200 thousand a month

201-350 thousand a month

351-450 thousand a month

451-600 thousand a month

601-750 thousand a month

751-900 thousand a month

More than 900 thousand a month

\section{Appendix B:}

Dear respondent please write about what you see in this picture (at least in 150 words)
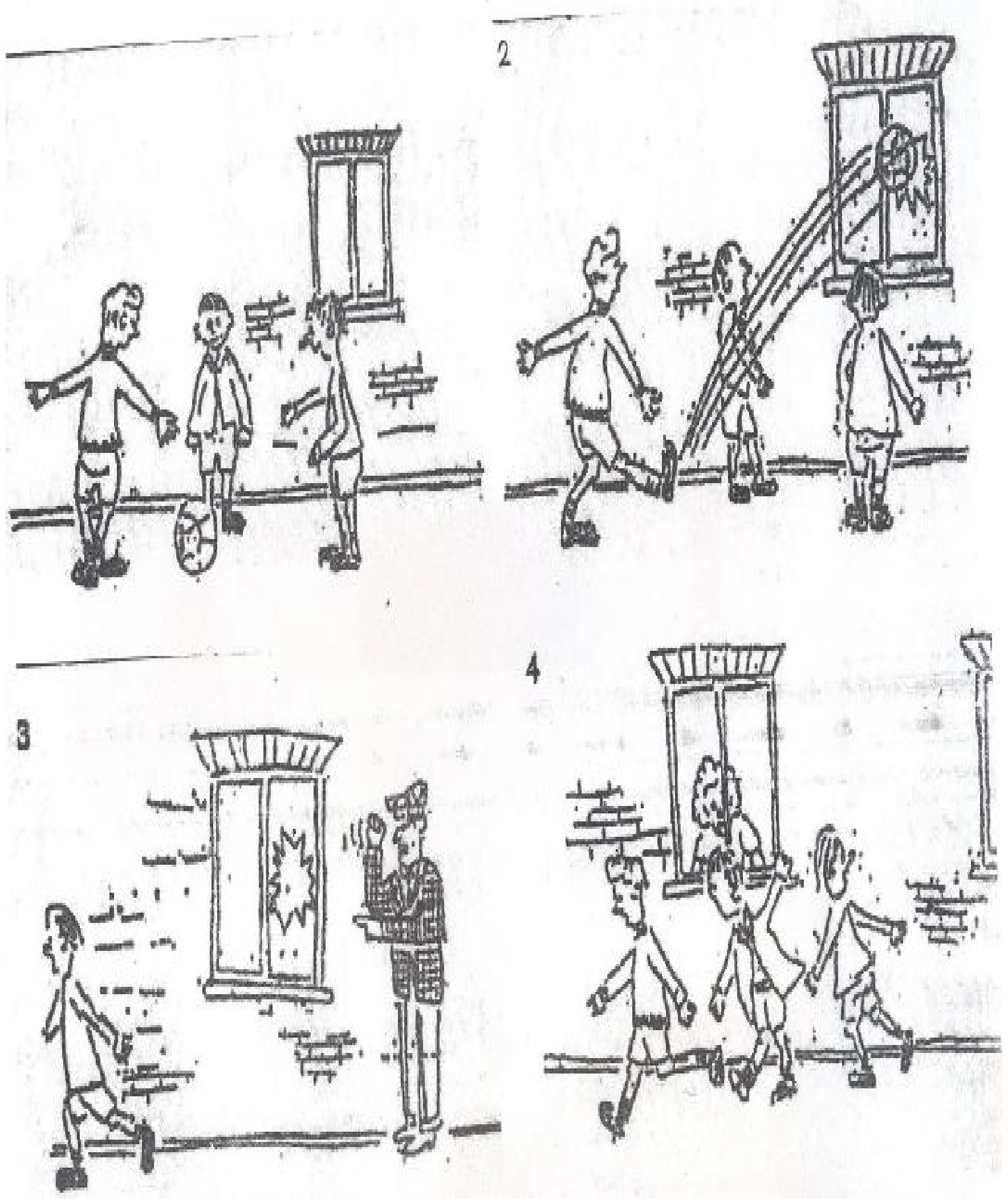